\title{
Titanium-Mediated Tribo-Chemically Activated Cold Welding of Aluminum
}

\author{
Abhay Kumar, P. Ganesh, Rakesh Kaul*, Puspen Mondal, Pragya Tiwari, A. K. Srivastava, R. K. Soni, \\ L. M. Kukreja
}

Raja Ramanna Centre for Advanced Technology, Indore - 452013 India

*Corresponding author: rkaul@rrcat.gov.in

Copyright (C) 2013 Horizon Research Publishing All rights reserved.

\begin{abstract}
The paper describes a new phenomenon of "titanium-mediated cold welding of aluminum" which was observed during development of titanium window for energetic electrons. During compression of two aluminum sheets with an intermediate titanium foil, the imposed tribological conditions developed at the mating interfaces of titanium/aluminum sheets activated a chemical reaction causing removal of alumina surface layer. Complete wear of titanium foil brought two virgin aluminum surfaces into intimate contact which resulted in their welding at room temperature. The phenomenon provides a new direction to facilitate cold welding between aluminum sheets.
\end{abstract}

Keywords Aluminum, Cold Welding, Tribo-Chemical Reaction, Titanium

\section{Introduction}

Cold welding of aluminum, invented in late 1940's by A. B. Sowter $[1,2]$ is a simple, cost effective and technologically important joining process overcoming many limitations of fusion welding, including porosity formation and solidification cracking $[3,4]$. Moreover, cold welding being a solid state joining process, does not introduce any thermal-induced microstructural changes around the welded joint. The process may also facilitate joining of dissimilar metals with wide difference in their thermo-physical properties and metallurgical incompatibility. On the other hand, process of cold welding introduces severe cold working around the weld joint which may alter properties of the weld region with respect to the bulk. Also, the process suffers from geometry-related limitation in its application to components. Bay [5] developed a theoretical model for estimating strength of a cold welded joint as a function of surface exposure and normal pressure. Pendrous et al [6] found that cold welding is initiated by the formation of transverse cracks in the surface layers of mating surfaces. Widening of these cracks during deformation allows extrusion of base metal through the cracks until a weld is formed. There are many reports on investigation of bond strength and threshold deformation of commercially pure aluminum specimens prepared by cold roll bonding $[7,8]$. Jamaati et al $[8,9]$ found that bond strength of roll bonded aluminium specimens increased with an increase in annealing time, friction coefficient and annealing temperature. Mahabunphachni et al [10] studied bond formation mechanism through microscopic analysis and developed and validated a model for bond strength prediction in pressure welds. Hosseini et al [11] have reported that peel strength of roll bonded bi-layer copper alloy strips increase with an increase in roll temperature and thickness reduction. The process of cold welding relies on extensive plastic deformation for fragmentation and dispersion of thin, tenacious and brittle $\mathrm{Al}_{2} \mathrm{O}_{3}$ surface film, which hampers its joining with other similar/dissimilar parts $[5,12]$. Various measures adopted to remove $\mathrm{Al}_{2} \mathrm{O}_{3}$ surface film to establish satisfactory cold welding include wire brushing [5,12] vacuum machining [13] and ion beam sputtering [14]. We have recently observed a novel phenomenon of titanium-activated cold welding of aluminum sheets during development of a titanium window for energetic electrons in an industrial particle accelerator. The forthcoming part of the paper presents results of our studies on this phenomenon.

\section{Experimental Details}

The procedure adopted for the fabrication of electron beam window referred above involved pressing of a composite assembly, comprising of a $50 \mu \mathrm{m}$ thick titanium foil (99.6\% purity) sandwiched between two $200 \mu \mathrm{m}$ thick aluminum gaskets of commercial purity, with a round-edged stainless steel (SS) tool of $4 \mathrm{~mm}$ radius of curvature (ROC). Under the point of loading, titanium foil was sheared and two aluminum gaskets were welded with an indistinguishable interface as shown in Figs. 1 A \& B. It should be noted that sheared parts of titanium foil were displaced from the cold welded region without being joined to aluminum. Similar experiments, performed without intermediate titanium foil, 
failed to establish joining between aluminum gaskets, thereby indicating important role played by titanium in facilitating cold welding.

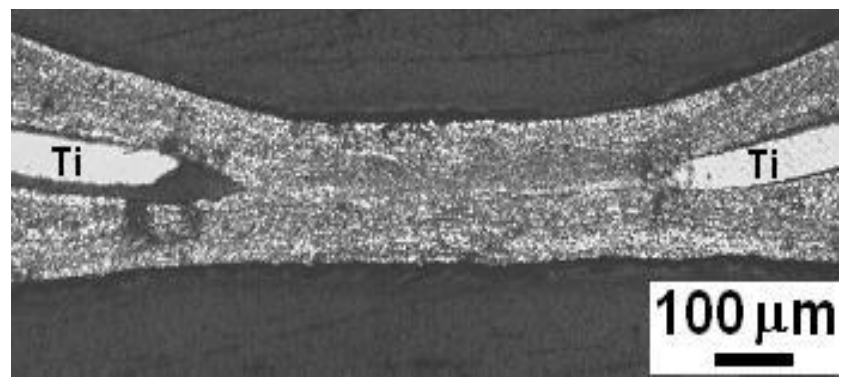

Figure 1A. Cross-section of cold welded Al gaskets showing cold welded region and sheared parts of intermediate Ti foil (ROC of pressing tool: 4 $\mathrm{mm})$

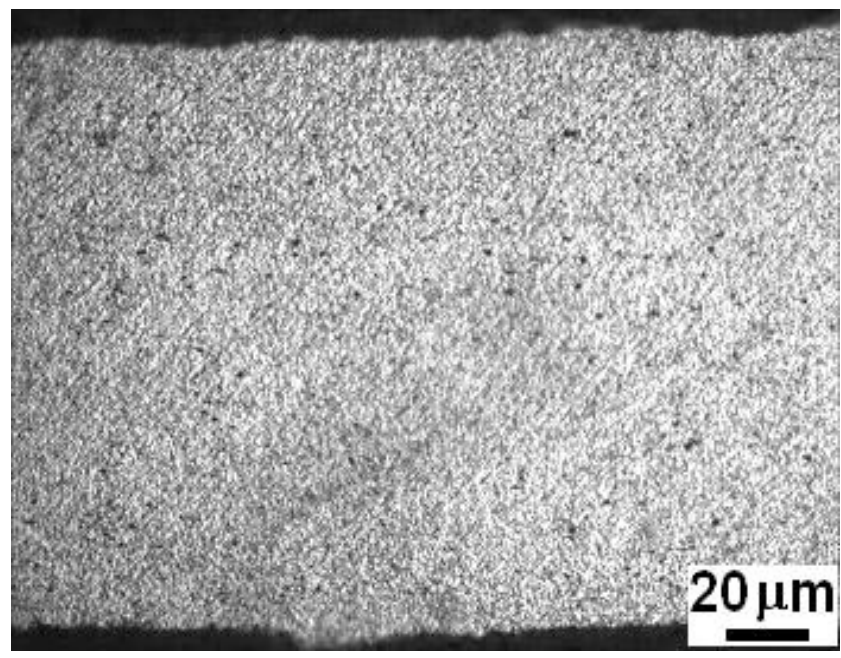

Figure 1B. Magnified view of the cold welded region in Figure 1A with indistinguishable welded interface

In order to systematically study the phenomenon, detailed experiments involving pressing of two aluminium sheets, with and without intermediate titanium foil (thickness $=50$ $\mu \mathrm{m}$ ), were performed in a controlled manner using a $150 \mathrm{kN}$ servo-hydraulic universal testing machine. The loading configuration is schematically shown in Fig. 2. Aluminum sheet specimens used for the experiments were cleaned with $1 \% \mathrm{HF}$ aqueous solution. Immediately before conducting the experiments, concerned sheets were swabbed with acetone to remove loose surface contamination including dust, oil, grease etc. It may be noted that in all cold welding experiments, $\mathrm{Al} / \mathrm{Ti} / \mathrm{Al}$ composite assembly was pressed at the rate of 1-2 $\mathrm{mm} / \mathrm{min}$. Table- 1 summarizes details of cold welding experiments on $\mathrm{Al}$ sheets of different thicknesses. The first set of experiments (referred as Set A) was conducted with a stainless steel tool of $4 \mathrm{~mm} \mathrm{ROC}$ at its pressing end. On the other hand, another set of experiments (referred as Set B) was performed with a relatively blunt pressing tool (cylindrical SS rod of $12.5 \mathrm{~mm} \mathrm{ROC)}$ while using thicker aluminum sheets (thickness $=1.6-2.3 \mathrm{~mm}$ ). It should be noted that Set B experiments were designed based on the feedback received from Set A. The main objective of using cylindrical SS tool of higher ROC was to suppress cutting action of pressing tool so that the fragmented particles of intermediate $\mathrm{Ti}$ foil were not completely removed from the weld site. The embedded Ti particles were expected to provide important signatures of events preceding establishment of $\mathrm{Al}-\mathrm{Al}$ cold welded joint. Relatively thicker aluminum sheets were used in Set B to obtain sufficient thickness of the joint region for preparation of specimens for transmission electron microscopy and evaluation of shear strength which is planned in the subsequent part of the study. The joint length is also increased from $15 \mathrm{~mm}$ in Set A to $25 \mathrm{~mm}$ in Set B to provide scope for discarding extensively deformed edge portions for preparation of shear test specimens. Cold welded Al-Al specimens were characterized by optical microscopy, scanning electron microscopy with energy dispersive spectroscopy (EDS) and cross-sectional transmission electron microscopy (TEM).
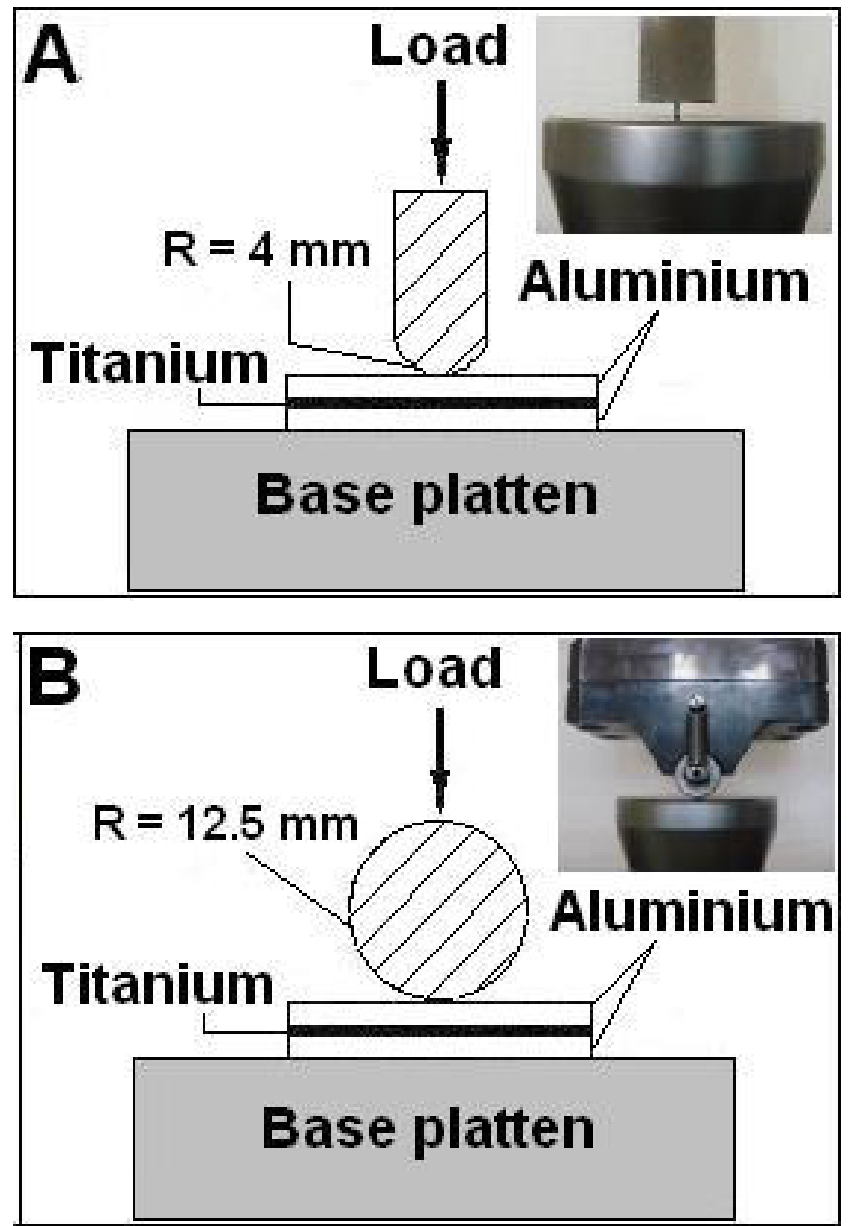

Figure 2. Schematic of experimental loading configurations (R: radius of curvature). The insets show the photograph of actual tool used. 
Table 1. Details of Cold Welding Experiments

\begin{tabular}{|c|c|c|c|c|c|}
\hline Specimen I/D & Upper sheet & Lower sheet & Intermediate foil & Max. load, kN & Result \\
\hline & Set A: Press & th plate tool (radiu & ure $=4 \mathrm{~mm}$ ); Joint & $15 \mathrm{~mm}$ & \\
\hline A1 & \multirow{7}{*}{$0.9 \mathrm{~mm}$ thick $\mathrm{Al}$} & \multirow{7}{*}{$0.9 \mathrm{~mm}$ thick $\mathrm{Al}$} & \multirow{3}{*}{$50 \mu \mathrm{m}$ thick $\mathrm{Ti}$} & 18 & $\begin{array}{l}\text { Ti sheared; no } \\
\text { welding }\end{array}$ \\
\hline A2 & & & & 18.3 & \multirow{2}{*}{ Welded } \\
\hline $\mathrm{A} 3$ & & & & 19 & \\
\hline A4 & & & No interlayer & 19 & Not welded \\
\hline $\mathrm{A} 5, \mathrm{~A} 6, \mathrm{~A} 7$ & & & $50 \mu \mathrm{m}$ thick $\mathrm{Ti}$ & 20 & Welded \\
\hline A8 & & & No interlayer & 20 & Not welded \\
\hline A9 & & & \multirow{2}{*}{$50 \mu \mathrm{m}$ thick $\mathrm{Ti}$} & 25 & Welded \\
\hline $\mathrm{A} 10, \mathrm{~A} 11, \mathrm{~A} 12$ & $1.5 \mathrm{~mm}$ thick $\mathrm{Al}$ & $1.5 \mathrm{~mm}$ thick $\mathrm{Al}$ & & 23 & Welded \\
\hline \multicolumn{6}{|c|}{$\begin{array}{c}\text { Set B: Pressing with cylindrical tool (diameter }=25 \mathrm{~mm} \text { ); Joint length }=25 \mathrm{~mm} \\
\text { Welding was achieved at (i) load } \geq 135 \mathrm{kN} \text { and (ii) reduction in total thickness } \geq 63-65 \%\end{array}$} \\
\hline B1 & $2 \mathrm{~mm}$ thick $\mathrm{Al}$ & $2 \mathrm{~mm}$ thick $\mathrm{Al}$ & \multirow{3}{*}{$50 \mu \mathrm{m}$ thick $\mathrm{Ti}$} & 144 & \multirow{3}{*}{ Welded } \\
\hline B2 & $2.3 \mathrm{~mm}$ thick $\mathrm{Al}$ & $2.3 \mathrm{~mm}$ thick $\mathrm{Al}$ & & 147 & \\
\hline B3 & $1.6 \mathrm{~mm}$ thick $\mathrm{Al}$ & $2 \mathrm{~mm}$ thick $\mathrm{Al}$ & & 145 & \\
\hline
\end{tabular}

\section{Results and Discussion}

Set A experiments consistently produced good cold welding joints between $0.9 \mathrm{~mm}$ thick and $15 \mathrm{~mm}$ wide aluminium sheet specimens with applied load greater than 18 $\mathrm{kN}$. In the absence of intermediate titanium foil, cold welding of aluminium sheets remained unsuccessful. For the given tool geometry, establishment of cold welding joints was found to be a function of applied load. It was observed that the applied load must be higher than that necessary to bring about shearing of titanium foil to establish contact between opposite faces of aluminium sheets. Cold welded joints were similar to that presented in Fig.1. Energy dispersive spectroscopic (EDS) analysis of the cold welded specimen did not show presence of $\mathrm{Ti}$ in the welded region.

Unlike Set A experiments, the titanium foil, sandwiched between the two aluminum sheets was not subjected to complete rupture in Set B experiments. Instead, titanium foil experienced progressive wear over a relatively larger area under the cylindrical tool. Figure 3 presents image of a worn intermediate titanium foil after an unsuccessful experiment where peak load was insufficient to establish satisfactory joints between two aluminum sheets. The state of the intermediate titanium foil, as shown in Fig. 3, suggests the loading conditions imposed in the Set B experiments facilitated intermittent regions of contact between opposite surfaces of aluminium sheets, separated by worn titanium particles. Cross-sectional metallographic examination of the resultant specimens also exhibited cold welded regions, separated by embedded titanium particles, as shown in Figure 4A. Like in Set A, no titanium was detected in the cold welded region (Fig.4B). The results clearly indicate that although presence of titanium did facilitate cold welding, the element was completely removed from the weld zone before the establishment of surface-to-surface contact for subsequent cold welding. It was found that in the satisfactorily cold welded specimens, reduction in total sheet thickness was $\geq 63-65 \%$. Many researchers have reported the need to achieve a material-dependent threshold deformation at the cleaned mating surfaces to obtain satisfactory cold welding [2, 6, 7]. Pendrous et al [6] reported that the threshold deformation required to achieve cold welding is dependent on geometry of the welding.

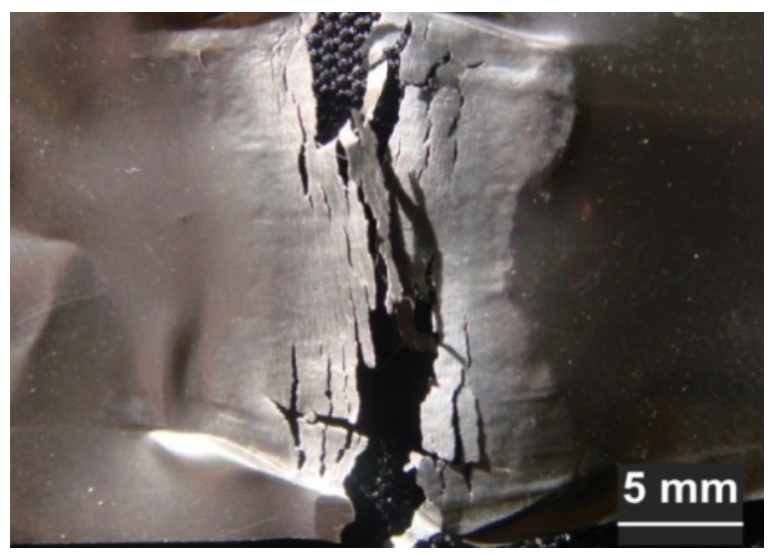

Figure 3. Severely worn titanium foil after an unsuccessful cold welding experiment conducted with cylindrical pressing tool of $12.5 \mathrm{~mm} \mathrm{ROC}$

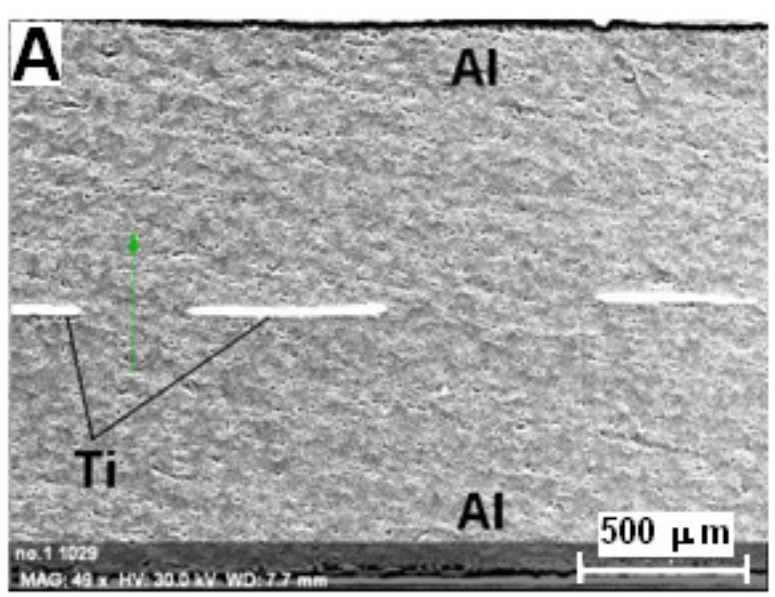




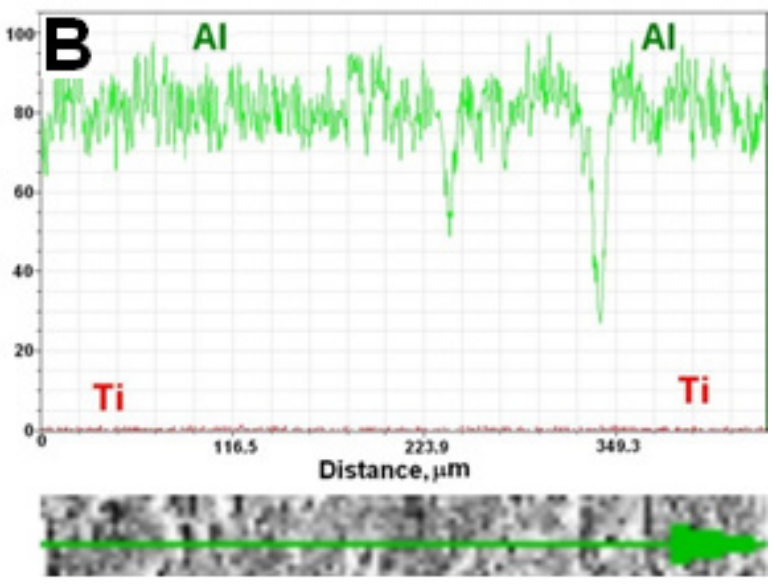

Figure 4. (A) Cross-section of cold welded specimen showing intermittent regions of cold welding between embedded Ti particles. (B) EDS line scans of $\mathrm{Al}$ and Ti across cold welded region, shown in Fig. 4A. Dips in Al profile is attributed to the presence of microgrooves and uneven topography on the etched surface. ROC of pressing tool: $12.5 \mathrm{~mm}$.

Examination of embedded titanium particle and aluminum interface (ref. Fig.5A) provided valuable signatures of events preceding cold welding. With respect to aluminum, titanium side of this interface exhibited relatively deeper $(\sim 10 \mu \mathrm{m})$ zone of alloying (Fig.5B). Another important observation was formation of aluminum titanate $\left(\mathrm{Al}_{2} \mathrm{TiO}_{5}\right)$, with pseudovbrookite orthorhombic structure, at the edge of embedded titanium particle (Fig.6), whereas its mating edge exhibited pure aluminum phase as shown in Figs.7A \& 7B. There was no evidence of the formation of $\mathrm{TiAl}_{3}$ or $\mathrm{TiAl}$, which reportedly form as a result of interfacial reaction of $\mathrm{Ti}$ and $\mathrm{Al}$ at high temperature $\left(516-680^{\circ} \mathrm{C}\right)[15,16]$. This may be due to inadequate local thermal exposure at $\mathrm{Ti} / \mathrm{Al}$ interface. Observation of $\mathrm{Al}_{2} \mathrm{TiO}_{5}$ on titanium side of $\mathrm{Ti} / \mathrm{Al}$ interface, suggests a tribo-chemical reaction between titanium and aluminum surfaces. Possible contributing factors for activating the interfacial reaction are: high local temperature and pressure, along with chemically active mechanically deformed surfaces formed under the imposed tribological conditions [17]. Tribo-chemically activated synthesis of $\mathrm{Al}_{2} \mathrm{TiO}_{5}$ has been reported during sliding wear of (Ti,Al)N (against corundum) and TiAlN/CrN coatings (against steel) $[18,19] . \quad \mathrm{Al}_{2} \mathrm{TiO}_{5}$ is generally formed through a solid-state reaction between $\mathrm{TiO}_{2}$ and $\alpha-\mathrm{Al}_{2} \mathrm{O}_{3}$ above $1280^{\circ} \mathrm{C}$, although its formation at lower temperature (over $600{ }^{\circ} \mathrm{C}$ ) is achieved through chemical methods of powder synthesis like co-precipitation [20].

Mechanical activation of reactant powder mixtures brings down synthesis temperature of $\mathrm{Al}_{2} \mathrm{TiO}_{5}$ [21]. On the other hand, high pressure enhances $\mathrm{Al}$ solubility in $\mathrm{TiO}_{2}$, thereby promoting $\mathrm{Al}_{2} \mathrm{O}_{3}$ dissolution which forms initial part of $\mathrm{Al}_{2} \mathrm{O}_{3} / \mathrm{TiO}_{2}$ reaction at high temperature leading to nucleation of $\mathrm{Al}_{2} \mathrm{TiO}_{5}[21,23]$. It is believed that under the experimental conditions, a tribo- chemical reaction, occurring between the oxide layers present on the surface of aluminum and titanium sheets, removed alumina surface film, thereby exposing virgin aluminum surfaces. With increasing pressure, titanium foil was completely worn at a number of places, thereby bringing in contact virgin aluminum surfaces for subsequent cold welding.
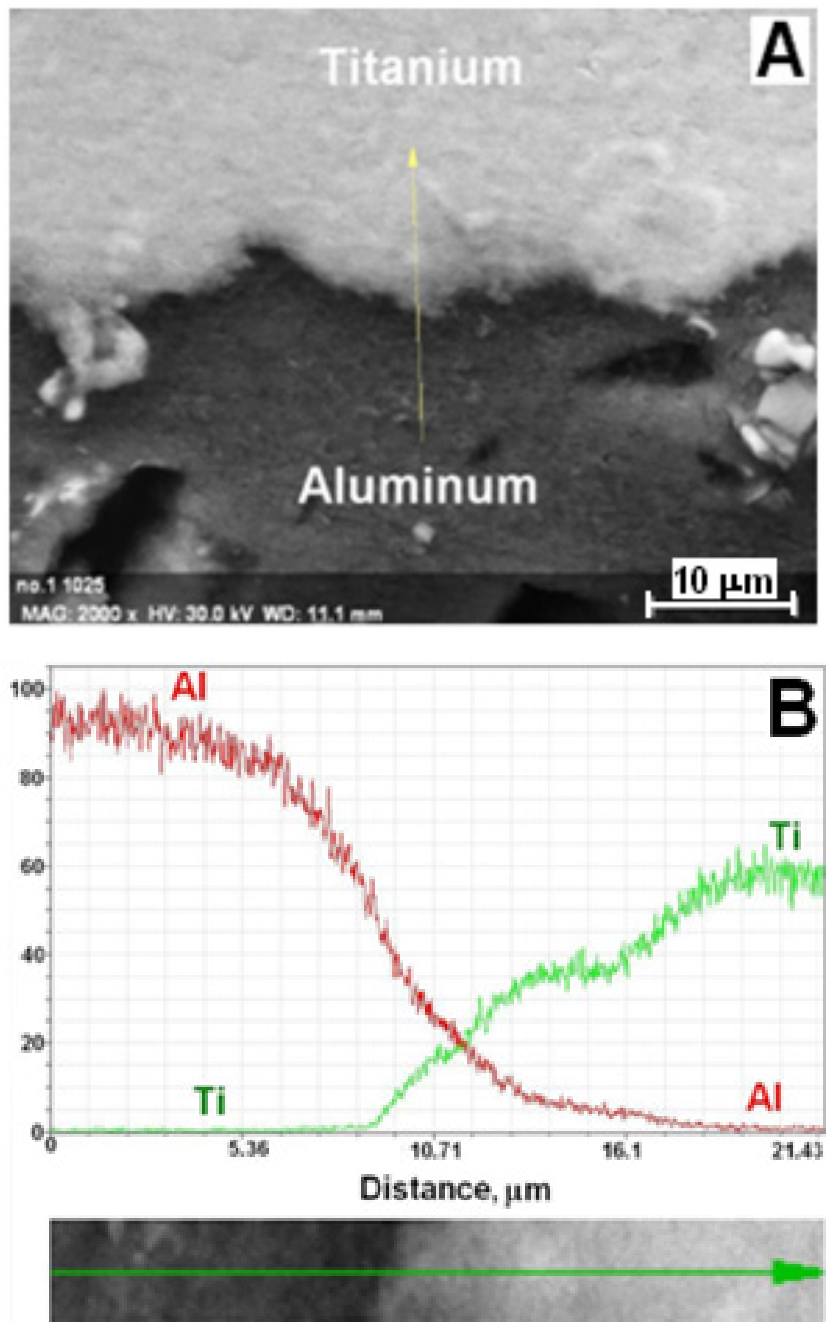

Figure 5. (A): SEM micrograph of Ti particle/Al matrix interface in the specimen made with cylindrical tool of $12.5 \mathrm{~mm}$ ROC; (B): EDS line scans of Al and Ti across embedded Ti particle/Al matrix interface

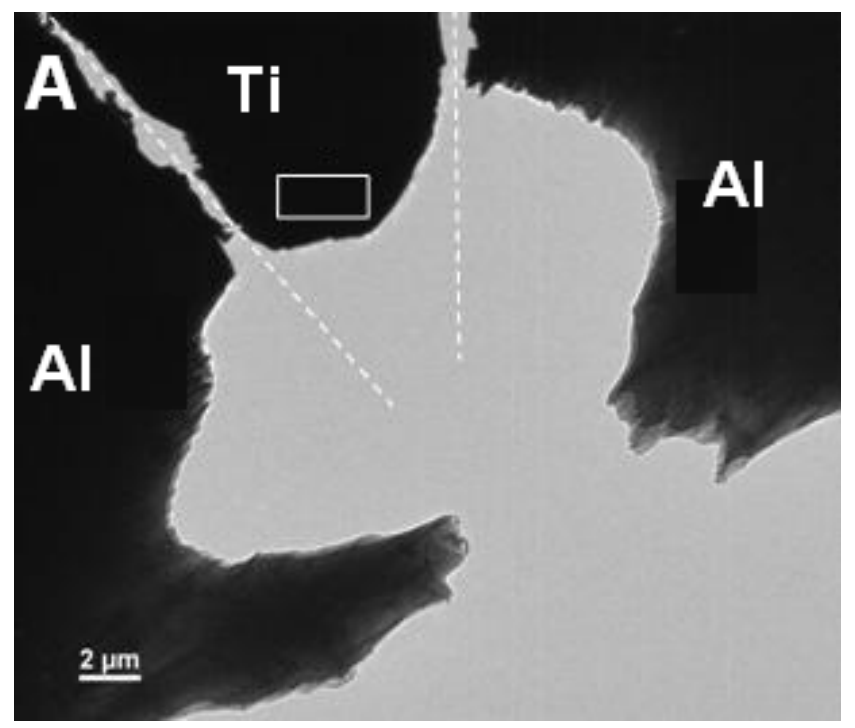




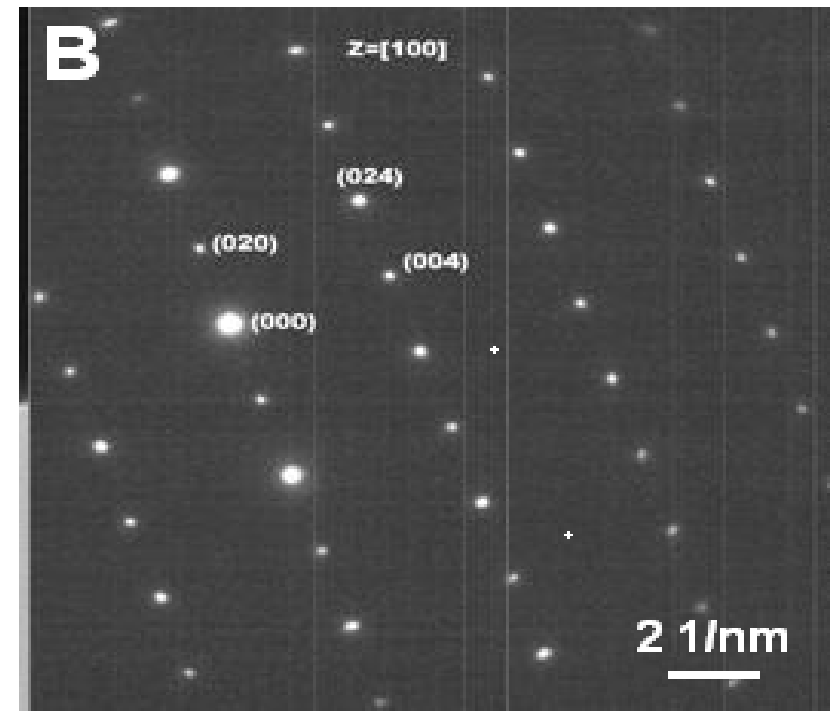

Figure 6. (A) Low magnification TEM image of cold welded region with embedded titanium particle in the aluminum matrix , (B) selected area electron diffraction pattern, obtained from titanium edge (area of analysis is marked as rectangle), corresponds to $\mathrm{Al}_{2} \mathrm{TiO}_{5}$ phase.
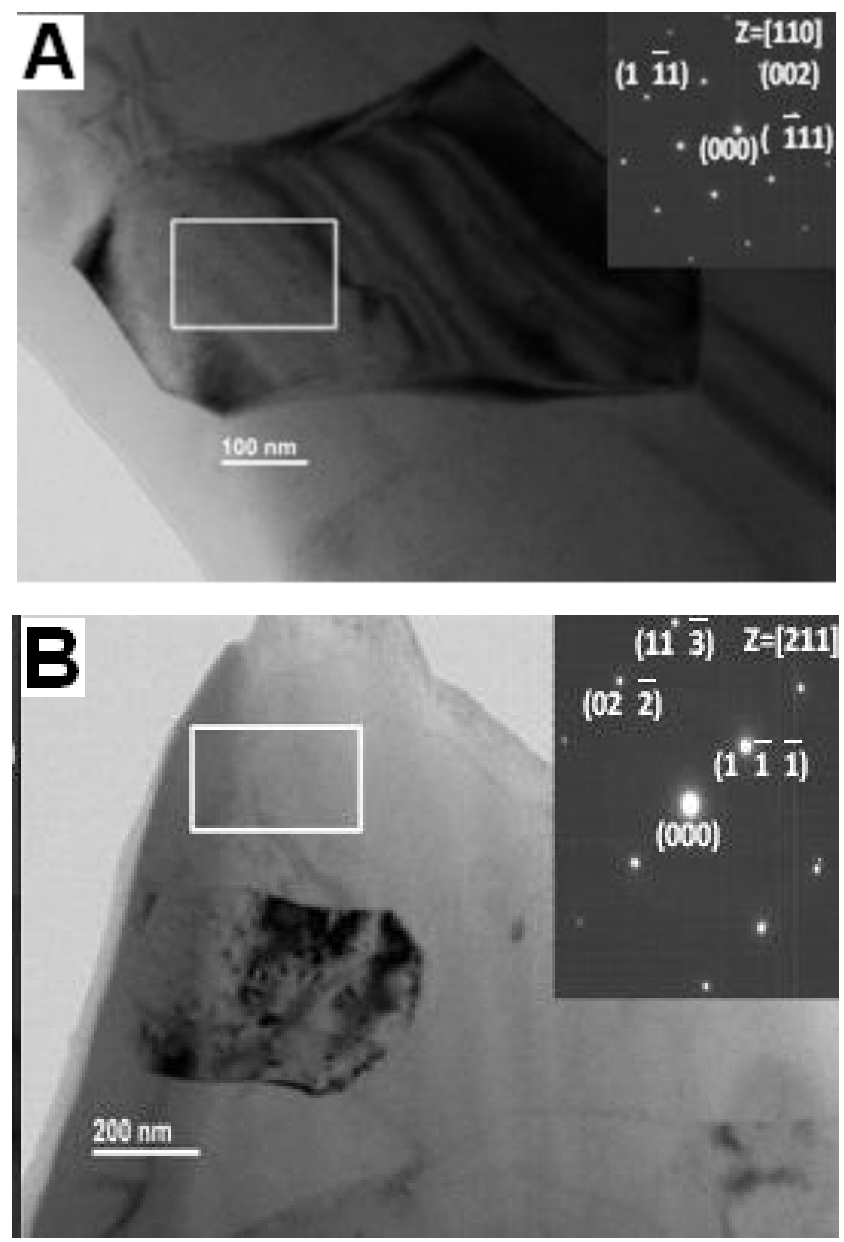

Figure 7. Microstructure and associated selected area diffraction patterns of two different locations (represented by rectangles) on the Al edge of $\mathrm{Ti} / \mathrm{Al}$ interface. Diffraction patterns shown in the inset confirm presence of pure $\mathrm{Al}$ phase in two different crystals with different orientations with zone axis [110] and [211] in figures (A) and (B), respectively.

\section{Conclusions}

The study unveils a new phenomenon of titanium-activated cold welding of aluminum at room temperature. The results suggest that chronology of events leading to establishment of Al-Al cold welds is: (i) tribo-chemical reaction between surface oxides of titanium and aluminum leading to the formation of $\mathrm{Al}_{2} \mathrm{TiO}_{5}$ on the surface of titanium (ii) complete shear/wear of titanium foil at a number of places depending on the radius of curvature of pressing tool - $\mathrm{Al}_{2} \mathrm{TiO}_{5}$ goes along with sheared/worn titanium, (iii) extrusion of virgin aluminum through openings in the titanium foil and (iv) Al-Al cold welding. The study provides a new approach of cold welding of aluminum parts at room temperature. Further studies are in progress to evaluate shear strength of the cold welded joints and analysis of the fracture surfaces to comprehend the nature of failure and mode of deformation in the joint region. Also attempts are being made to apply this methodology to join other similar and dissimilar combinations like copper to copper and aluminum to copper etc.

\section{Acknowledgements}

Authors' are very grateful to Mr. Dinesh Nagpure and Mr. Ram Niha Ram for their technical help.

\section{REFERENCES}

[1] A. B. Sowter. Materials joined by new cold welding process, Materials and Methods Vol. 2, 60-63, 1948

[2] A. B. Sowter. Cold pressure welding. U. S. Patent 2522408 , 1950.

[3] W. Tuttle. Understanding aluminum welding. Welding Journal, Vol. 70(2), 43-46, 1991.

[4] N.Coniglio, C. E.Cross, T. Michael, M. Lammers. Defining a critical weld dilution to avoid solidification cracking in aluminum, Welding Journal, Vol. 87, 237s-247s, 2008.

[5] N. Bay. Mechanisms producing metallic bonds in cold welding, Welding Journal, Vol. 62, 137s-142s, 1983.

[6] R. C. Pendrous, A. N. Bramley, G. Pollard. Cold roll and indent welding of some metals, Metals Technology, Vol. 11, 280-289, 1984.

[7] M. Eizadjou, H. D. Manesh, K. Janghorban. Investigation of roll bonding between aluminum alloy strips. Materials and Design, Vol. 29, 909-913, 2008.

[8] R. Jamaati, M. R. Toroghinejad. Effect of friction, annealing conditions and hardness on the bond strength of $\mathrm{Al} / \mathrm{Al}$ strips produced by cold roll bonding process, Materials and. Design, 
Vol. 31, 4508-4513, 2010.

[9] R. Jammati, M. R. Toroghinejad. Cold roll bonding bond strengths, Review of Materials Science and Technology, Vol. 27, 1101-1108, 2011.

[10] Mahabunphachai, S.; Kos, M.; Li, J. Pressure welding of thin sheet metals: Experimental investigations and analytical modeling. Journal of Manufacturing Science and Engineering, Vol. 131, 041003-1 - 041003-9, 2009.

[11] S. A. Hosseini, M. Hosseini, H. D. Manesh. Bond strength evaluation of roll bonded bi-layer copper alloy strips in different rolling conditions, Materials and Design, Vol. 32, 76-81, 2011.

[12] A. B. Sowter. Cold pressure welding. Journal of the British Institution of Radio Engineers, Vol. 10, 404-406, 1950.

[13] W. C. Sherwood, D.R. Milner. The effect of vacuum machining on cold welding of metals. Journal of the Japan Institute of Metals, Vol.97, 1-5, 1969.

[14] B. L. States. Method of cold welding using ion beam technology, U. S. Patent 4245768, 1981.

[15] Luo, J-G.; Acoff, V. Interfacial reactions of titanium and aluminum during diffusion welding. Welding Journal, Vol. $79,239 \mathrm{~s}-243 \mathrm{~s}, 2000$

[16] F. J. J. Van Loo, G. D. Rieck. Diffusion in the Ti-Al system I. Interdiffusion between solid $\mathrm{Ti}$ and $\mathrm{Ti}$ or $\mathrm{Ti}-\mathrm{Al}$ system,
Acta Meterialia, Vol. 21, 61-71, 1973.

[17] G. Heinicke. Tribochemistry, Carl Hanser Verlag Munchen Wien, Berlin, Germany, 1984.

[18] E. Vancoille, J. P. Celis, N. S. Roos. Dry Sliding Wear of TiN based Ternary PVC Coatings, Wear, Vol. 165, 41-49, 1993.

[19] Q. Luo, W. M. Rainforth. W.D. Münz. Wear mechanisms of monolithic and multicomponent nitride coatings grown by combined arc etching and unbalanced magnetron sputtering, Surface and Coatings Technology, Vol. 146-147, 430-435, 2001.

[20] R. Camaratta, W. Acchar, C. P. Bergmann. Phase transformations in the $\mathrm{Al}_{2} \mathrm{O}_{3} / \mathrm{TiO}_{2}$ system and metastable phase formation at low temperatures. Reviews on Advanced Materials Science, Vol. 27, 64-68, 2011.

[21] C. Xiaohu, Q. Lang, C. Zhouping, Z. Hunag, C. Xiaomin, L. Jun. Anisotropic grain growth of $\mathrm{Al}_{2} \mathrm{TiO}_{5}$ powers synthesized through mechanical activation, Journal of Ceramics, Vol. 27, 88-91, 2006.

[22] A. Escudero, F. Langenhorst, W. F. Müller. Aluminum solubility in $\mathrm{TiO}_{2}$ rutile at high pressure and experimental evidence for a $\mathrm{CaCl}_{2}$-structured polymorph, American Mineralogist, Vol. 97, No. 7, 1075-1082, 2012.

[23] B. Freudenberg, A. Mocellin. Aluminium titanate formation by solid state reaction of $\mathrm{Al}_{2} \mathrm{O}_{3}$ and $\mathrm{TiO}_{2}$ single crystals. Journal of Materials Science, Vol. 25, 3701-3708, 1990. 